\title{
Non-invasive interventions in idiopathic scoliosis: a systematic review
}

\section{Intervenções não invasivas na escoliose idiopática: revisão sistemática}

\author{
André Ivaniski Mello[a], Ana Carolina Kanitz ${ }^{[\mathrm{b}]}$, Flávia Gomes Martinez ${ }^{[\mathrm{a}]^{*}}$
}

[a] Universidade Federal do Rio Grande do Sul (UFRGS), Porto Alegre, RS, Brazil

[b] Universidade Federal de Uberlândia (UFU), Uberlândia, MG, Brazil

\begin{abstract}
Introduction: Idiopathic Scoliosis (IS) is an idiopathic curvature of the spine in all three plans, been treated conservatively (non-invasive) or surgicaly (invasive). The effectiveness of noninvasive therapy still remains lacking in a scientific basis to support their evidence-based applicability. Objective: Evaluate the effects of non-invasive interventions in spine lateral inclination in IS through a systematic literature review. Methods: The search of studies in MEDLINE, SCOPUS and COCHRANE databases was performed on 24th March, 2014. The terms used were: Scoliosis, therapeutic exercise, physical therapy. Clinical trials with scoliotic patients undergoing some type of non-invasive intervention were included. The outcome was spine lateral inclination. Results: The research found 941 studies, seven of these were included after a screening performed by two independent reviewers. Six studies (85.7\%) have adopted some sort of kinesiotherapeutic technic, and three studies (42.8\%) used corrective orthosis. The average intervention time in kinesiotherapeutic technique studies was of 37.6 weeks and 91.6 weeks in the studies of corrective brace. The progression improvement of the spine lateral inclination was reported by $83.3 \%$ ( 5 of 6 ) of the kinesiotherapeutic technique studies and in $66.6 \%$ (2 of 3) of studies with corrective brace. Conclusion: An improvement was found, in general, in the progression of spine lateral inclination in IS subjects of both sexes from 11 to 25 years of age undergoing non-invasive interventions.
\end{abstract}

Keywords: Scoliosis. Physical Therapy Modalities. Posture. Review.

\footnotetext{
AIM : BS, e-mail : andremello92@hotmail.com

ACK : PhD, e-mail : ana_kanitz@yahoo.com.br

FGM : PhD, e-mail : flavia.martinez@ufrgs.br
} 
Introdução: A Escoliose Idiopática (IS) é uma curvatura idiopática da coluna vertebral nos três planos de tratamento conservador (não invasivo) ou cirúrgico (invasivo). Ainda assim, a efetividade da terapêutica não invasiva permanece carente de um embasamento científico que suporte sua aplicabilidade baseada em evidências. Objetivo: avaliar os efeitos de intervenções não invasivas sobre inclinação lateral da coluna IS por meio de uma revisão sistemática da literatura. Métodos: Foi realizada uma busca de estudos nas bases de dados MEDLINE, SCOPUS e COCHRANE, em 24 de março de 2014. Os termos utilizados foram: scoliosis, exercise therapy, physiotherapy, physical therapy. Foram incluídos ensaios clínicos com indivíduos escolióticos submetidos a algum tipo de intervenção não invasiva. O desfecho incluído foi inclinação lateral da coluna. Resultados: $A$ busca inicial resultou em 941 estudos, com 07 estudos incluídos após triagem de dois revisores independentes. Seis estudos (85,7\%) adotaram algum tipo de técnica cinesioterapêutica, e três estudos (42,8\%) valeram-se do uso de órtese corretiva. O tempo de intervenção médio nos estudos com técnica cinesioterapêutica foi de 37,6 semanas, e de 91,6 semanas nos estudos com órtese corretiva. A melhora na progressão da inclinação lateral da coluna foi relatada em 83,3\% (5 de 6) dos estudos com técnica cinesioterapêutica, e em 66,6\% (2 de 3) dos estudos com órtese corretiva. Conclusão: Foi encontrada uma melhora, de maneira geral, na progressão da inclinação lateral da coluna na IS em sujeitos de ambos os sexos de 11 a 25 anos de idade submetidos a intervenções não invasivas.

Palavras-chave: Escoliose. Fisioterapia. Postura. Revisão.

\section{Introduction}

Idiopathic Scoliosis (IS) is an idiopathic curvature of the spine in the three planes (frontal, sagittal and transverse), with a greater component of lateral deviation of at least $10^{\circ}(1,2)$. From unknown etiology (3), it has a prevalence of 2 to $3 \%$ in adolescents $(4,5)$, representing $30 \%$ of all cases of postural deviations (1). It affects more females in a ratio of $4: 1$ in curves greater than $10^{\circ}$, and in the ratio of $5: 1$ in curves higher than $30^{\circ}(6)$.

The IS can affect the social sphere, limiting job opportunities, social isolation and lower marriage rates (7), moreover interferes negatively on self image $(8,9)$ and stress level $(10)$. IS progression can result in back pain, reduced mobility and lung function (11), postural stability deficit (12 - 14), muscle force imbalance $(15,16)$, altered electromyographic activity (17), increased risk of lumbar and thoracic pain and degenerative diseases of the intervertebral $\operatorname{disc}(18,19)$.

IS can be treated both conservatively in a non-invasively intervention, as well as by invasive surgical intervention. In curvatures up to $25^{\circ}$ the treatment is observational, with periodic radiological exams. Above $25^{\circ}$ corrective braces are used for the treatment of IE. Surgical interventions, in turn, are recommended in cases of bone immaturity with curves of $40^{\circ}$ to $45^{\circ}$, or of bone maturity with curves greater than $50^{\circ}(20,21)$. Conservative interventions for treatment of IS include kinesiotherapeutic techniques, corrective orthoses, electrical stimulation, manual therapy, acupuncture, foot orthosis, traction and observation (5, 22 - 30).

The use of corrective orthoses in the treatment of IE has controversial reports in the literature and its effectiveness is not well established yet $(5,22,31)$. Although some studies have demonstrated positive effects on IE $(23,32)$, several authors point out the need of trials with greater methodological robustness to quantify the efficacy of corrective orthoses in this postural deviation $(5,31,32)$. Similarly, the benefits of kinesiotherapeutic techniques in the treatment of IE are not well defined too $(5,25)$. Authors stand up for better methodological quality studies $(23,25)$ in order to properly evaluate the effects of physical exercise treatment on IE.

Considering the absence, in the literature, of proper effects' studies about non-invasive conservative treatment on the progression of IE, clinical trial data survey of the area are justified. Therefore the aim of this study was to evaluate the 
effects of non-invasive interventions on the spine lateral inclination in IS through a systematic review of the literature.

\section{Methods}

Clinical studies were icluded along with original data about scoliotic subjects submitted to some type of noninvasive intervention, in comparision to a control group or another type of intervention. The outcome was a lateral spine inclination. Studies without a control or a comparator group, in languages other than English or Portuguese, that did not present the outcome of interest, which reported data from another study, or have subjects with comorbidities were all excluded.

The studies search was carried out in the following databases: MEDLINE (accessed via PubMed), SCOPUS and COCHRANE. In addition manual search was done based on the references of the studies found through the databases. The search was conducted on 24th March, 2014, with the following terms in English: "scoliosis", "exercise therapy", "physiotherapy", "physical therapy". The complete search strategy used for PubMed can be seen in Table 1.

Table 1 - Search strategy used in PubMed

\begin{tabular}{ll}
\hline \#1 & "Scoliosis" [Mesh] OR "scoliosis" OR "scoliosis" \\
\hline \#2 & "Exercise Therapy" [Mesh] OR "Exercise Therapy" \\
& or "Therapy, Exercise" OR "Exercise Therapies" OR \\
& "Therapies, Exercise" OR "Physical Therapy Modalities" \\
& [Mesh] OR "Physical Therapy Modalities" OR \\
& "Modalities, Physical Therapy "OR" Physical Therapy \\
& Techniques "OR" Physical Therapy Techniques "OR" \\
& Physical Therapy Techniques "OR" Physical Therapy \\
& Techniques "OR" Physiotherapy (Techniques) "OR" \\
\hline \# 3 & \# 1 AND \# 2
\end{tabular}

The titles and abstracts of all studies found were independently assessed by two reviewers. Those studies which did not provide sufficient information for the inclusion and exclusion criteria were selected for full text reading. In this second stage, the reviewers independently assessed the studies and selected those who met the eligibility criteria. Disagreements among reviewers were resolved by consensus.

The methodological quality of each study was assessed using the PEDro scale. The PEDro scale considers 10 distinct items, scoring 1 point for each item contemplated by the study. The evaluated items are: 1) If the subjects were randomly assigned to groups; 2) If the subjects distribution was blind; 3) If, initially, the groups were similar of the most important prognostic indicators; 4) If all subjects blindly participated in the study; 5) If all the physical therapists who administered the therapies have done them blindly aswell; 6) If all the evaluators who measured at least one key result did it blindly too; 7) If measurements of at least one key result were obtained in more than $85 \%$ of the subjects initially distributed by the groups; 8) If all the subjects received the treatment or control condition, or were analyzed by an intention to treat when appropriate; 9) If a statistical intergroup comparison was performed; $10)$ If the study presents precision and variability measurements. Those studies without a clear description of the methodological criteria did not receive the score for such items.

\section{Results}

The initial databases search resulted in 941 studies. Of these, 11 were excluded because they were duplicated, 908 excluded because they did not fit into the subject of interest after reading the title and/or the abstract. What left 31 studies, of which 08 were excluded for been written in Polish, and 06 due to the impossibility of obtaining the original article. Of the 23 studies selected for reading the full text, 15 were excluded because they did not include control or comparator group; 01 because it was a case study and 01 because it conttained a post-surgical intervention. Finally 07 studies were included in this review analysis. Figure 1 shows the flowchart of the included studies and Table 2 summarizes the characteristics of these studies. 


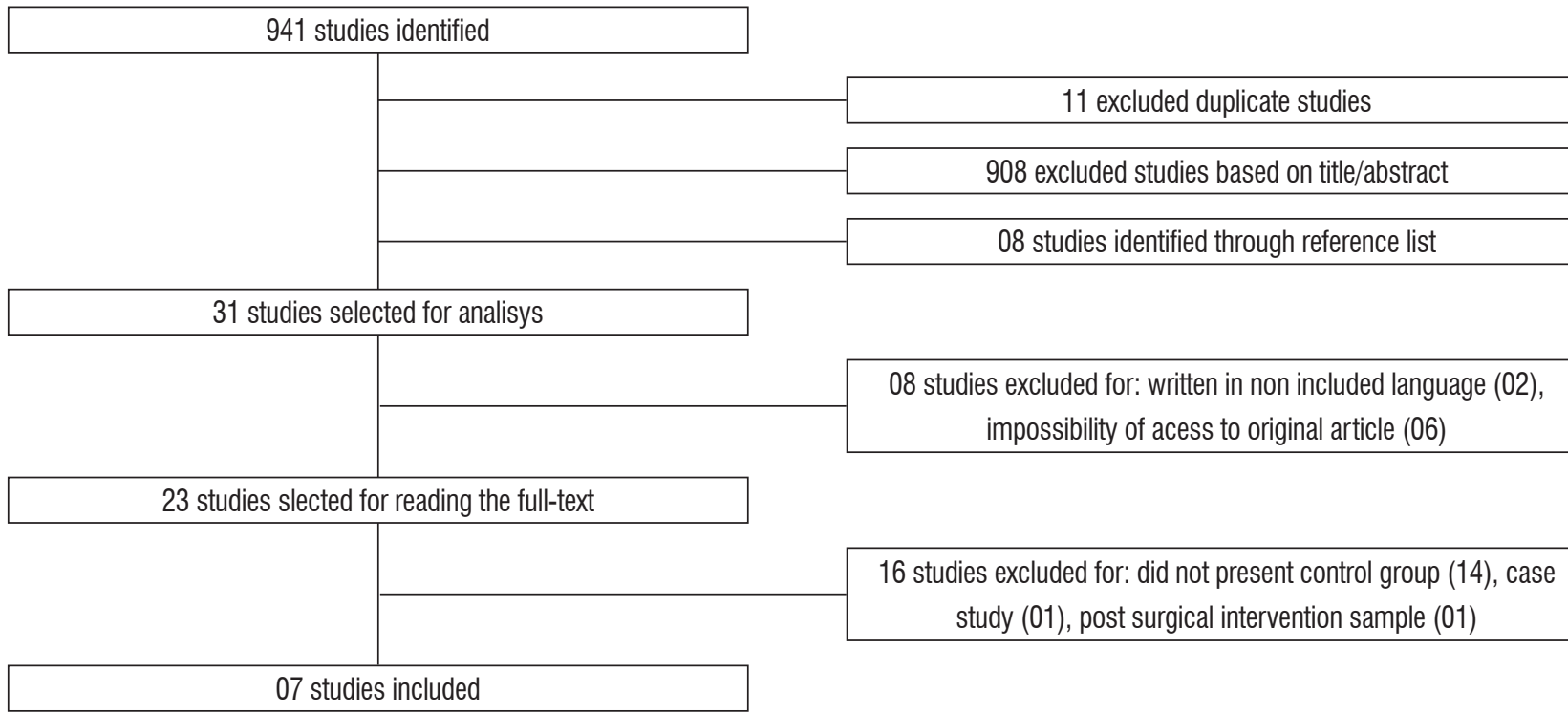

Figure 1 - Flowchart of the studies included in the review.

Table 2 - Characteristics of included studies

\begin{tabular}{|c|c|c|c|c|c|c|c|}
\hline \multirow[t]{2}{*}{ Study } & \multirow{2}{*}{$\begin{array}{l}\text { Type of } \\
\text { Intervention }\end{array}$} & \multirow{2}{*}{$\begin{array}{l}\mathrm{N} \\
\text { sample }\end{array}$} & \multirow[t]{2}{*}{$\mathrm{Age}^{\mathrm{a}}$} & \multirow[t]{2}{*}{ Sex } & \multirow[t]{2}{*}{ Intervention Details } & \multicolumn{2}{|c|}{ Spine lateral inclination } \\
\hline & & & & & & Pre & Post \\
\hline $\begin{array}{l}\text { de Araujo } \\
\text { et al. (33) }\end{array}$ & $\begin{array}{l}\text { Pilates vs. } \\
\text { Control }\end{array}$ & $20 / 11$ & $18-25$ & $\mathrm{~F}$ & $\begin{array}{l}\text { Pilates: } 60 \text { min, 2x/week, } \\
12 \text { weeks. }\end{array}$ & $\begin{array}{l}7.6 \pm 3.5^{\circ} / \\
7.1 \pm 2.8^{\circ}\end{array}$ & $\begin{array}{l}4.8 \pm 2.0^{\circ} \\
(p=0.0001) / \\
6.9 \pm 3.1^{\circ} \\
(p=0.676)\end{array}$ \\
\hline Diab (34) & $\begin{array}{l}\text { Physiotherapy } \\
\text { vs. } \\
\text { Physiotherapy } \\
\text { + forward } \\
\text { head correction } \\
\text { program }\end{array}$ & $38 / 38$ & $\begin{array}{l}13.2 \pm 1.2 / \\
14.5 \pm 1.3\end{array}$ & F/M & $\begin{array}{l}\text { Physical therapy } \\
\text { (stretching and } \\
\text { strengthening): 3x/week; } \\
10 \text { weeks. } \\
\text { Physiotherapy + } \\
\text { corrective exercises: } 4 x / \\
\text { week, } 10 \text { weeks. }\end{array}$ & $\begin{array}{l}16.8 \pm 2.3^{\circ} \\
15.1 \pm 1.8^{\circ} \\
(p>0.5)\end{array}$ & $\begin{array}{l}14.3 \pm 2.3^{\circ} \\
14.5 \pm 1.6^{\circ} \\
(p=0.001)\end{array}$ \\
\hline $\begin{array}{l}\text { Gammon } \\
\text { et al. (35) }\end{array}$ & $\begin{array}{l}\text { SpineCor brace } \\
\text { vs. TLSO brace }\end{array}$ & $32 / 35$ & $\begin{array}{l}13.2 \pm 1.3 / \\
13.0 \pm 1.3\end{array}$ & $\mathrm{~F} / \mathrm{M}$ & $\begin{array}{l}\text { SpineCor (20h/day, } 30.5 \\
\text { months). } \\
\text { TLSO (23h/day; } 24.5 \\
\text { months) }\end{array}$ & $\begin{array}{l}31.0 \pm 5.02^{\circ} / \\
32.7^{\circ} \pm 4.97 \\
(p=0.16)\end{array}$ & $\begin{array}{l}37.7^{\circ} \pm 9.4^{\circ} \\
37.5 \pm 10.8^{\circ} \\
(p=0.95)\end{array}$ \\
\hline $\begin{array}{l}\text { Negrini et } \\
\text { al. (36) }\end{array}$ & $\begin{array}{l}\text { SEAS vs. } \\
\text { Conventional } \\
\text { Physiotherapy }\end{array}$ & $35 / 39$ & $\begin{array}{l}12.7 \pm 2.2 / \\
12.1 \pm 2.1\end{array}$ & F/M & $\begin{array}{l}\text { SEAS: } 40 \text { min, } 2 x / \text { week, } \\
48 \text { weeks. } \\
\text { Physiotherapy: } 45 \text { to } 90 \\
\text { min, } 2 \text { to } 3 x / \text { week, } 48 \\
\text { weeks. }\end{array}$ & $\begin{array}{l}\text { SEAS: } 0.67^{\circ} \text { reduction } \\
(p<0.05) / \\
\text { Physiotherapy: increase } \\
\text { of } 1.38^{\circ}(p<0.05) \text {. }\end{array}$ & \\
\hline $\begin{array}{l}\text { Negrini et } \\
\text { al. (37) }\end{array}$ & $\begin{array}{l}\text { Exercises + } \\
\text { Risser brace } \\
\text { vs. Exercises } \\
+ \text { brace }(23 \mathrm{~h} / \\
\text { day) or ( } 21 \mathrm{~h} / \\
\text { day) or (18h/ } \\
\text { day) vs. Active } \\
\text { self corrective } \\
\text { exercises }\end{array}$ & $\begin{array}{l}2 / 14 / \\
23 / 7 / 2\end{array}$ & $\begin{array}{l}11.4 \pm 0.1 / \\
13.2 \pm 1.7 / \\
13.0 \pm 1.5 / \\
12.4 \pm 1.8 / \\
11.6 \pm 1.9\end{array}$ & F/M & $\begin{array}{l}\text { Exercises, braces } \\
\text { (Risser, Lyon, Sforzesco- } \\
\text { SPoRT, Sibilla-Chêneau, } \\
\text { Lapadula) (23h/day, } 21 \mathrm{~h} / \\
\text { day, } 18 \mathrm{~h} / \text { day) and active } \\
\text { corrective exercises: } 4.2 \\
\pm 1.4 \text { years }\end{array}$ & $\begin{array}{l}29.5 \pm 6.4^{\circ} \% \\
34.5 \pm 3.9^{\circ} \% \\
28.2 \pm 3.3^{\circ} \% \\
31.1 \pm 27^{\circ} \% \\
26.0 \pm 1.1^{\circ} \\
(C 23>C 21)^{\star} \\
(C 18>C 21)^{\star *}: \\
(p<0.05)\end{array}$ & $\begin{array}{l}-15.0 \pm 26.9^{\circ} \\
(p>0.05) / \\
-6.4 \pm 9.8^{\circ} \\
(p<0.05) / / \\
-7.5 \pm 6.4^{\circ} \\
(p<0.05) / \\
-6.6 \pm 5.4^{\circ} \\
(p<0.05) / \\
+1.5 \pm 0.7^{\circ} \\
(p>0.05)\end{array}$ \\
\hline
\end{tabular}

(To be continued) 
Table 2 - Characteristics of included studies

(Conclusion)

\begin{tabular}{|c|c|c|c|c|c|c|c|}
\hline \multirow[t]{2}{*}{ Study } & \multirow{2}{*}{$\begin{array}{l}\text { Type of } \\
\text { Intervention }\end{array}$} & \multirow{2}{*}{$\begin{array}{l}\mathrm{N} \\
\text { sample }\end{array}$} & \multirow[t]{2}{*}{$\mathrm{Age}^{\mathrm{a}}$} & \multirow[t]{2}{*}{ Sex } & \multirow[t]{2}{*}{ Intervention Details } & \multicolumn{2}{|c|}{ Spine lateral inclination } \\
\hline & & & & & & Pre & Post \\
\hline $\begin{array}{l}\text { Weiss \& } \\
\text { Klein (38) }\end{array}$ & $\begin{array}{l}\text { Schroth Method } \\
\text { vs. Schroth } \\
\text { method + } \\
\text { Physiologic } \\
\text { program }\end{array}$ & $18 / 18$ & $\begin{array}{l}15.3 \pm 1.1 / \\
14.7 \pm 1.3\end{array}$ & $\mathrm{~F}$ & $\begin{array}{l}90 \text { min, } 5 x / \text { week, } \\
4 \text { weeks }\end{array}$ & $\begin{array}{l}\text { Schroth: reduction of } \\
0.32 \pm 2.5 \mathrm{~mm} \\
(p=0.6) \text { in the lateral } \\
\text { inclination. } \\
\text { Schroth + physio-logic: } \\
\text { reduction of } 2.32 \pm 3.8 \\
\mathrm{~mm}(p=0.02) \text { in the } \\
\text { lateral inclination. }\end{array}$ & \\
\hline $\begin{array}{l}\text { Zaina et } \\
\text { al. (39) }\end{array}$ & $\begin{array}{l}\text { SpineCor } \\
\text { brace }^{1} \text { vs. } \\
\text { SEAS/SpineCor } \\
\text { brace }^{2} \text { vs. } \\
\text { Sport brace }\end{array}$ & $\begin{array}{l}28 / 28 / \\
29 / 74\end{array}$ & $\begin{array}{l}13 \pm 1 / \\
13 \pm 1 / \\
13 \pm 1 / \\
13 \pm 1\end{array}$ & $\mathrm{~F} / \mathrm{M}$ & $\begin{array}{l}\text { SpineCor }{ }^{1}: 20 \mathrm{~h} / \text { day, } \\
17 \pm 4 \text { months; } \\
\text { SEAS: } 14 \pm 4 \text { months; } \\
\text { SpineCor }{ }^{2}: 20 \mathrm{~h} / \text { day, } \\
17 \pm 4 \text { months; } \\
\text { Sport: } 18-23 \mathrm{~h} / \text { day, } \\
18 \pm 4 \text { months. }\end{array}$ & $\begin{array}{l}\text { SpinerCor }{ }^{1}: 22 \pm 4^{\circ} \\
\text { SEAS: } 20 \pm 4^{\circ} \\
\text { SpinerCor }{ }^{2}: 22 \pm 4^{\circ} \\
\text { Sport: } 25 \pm 4^{\circ}\end{array}$ & $\begin{array}{l}\text { SpinerCor }{ }^{1:} \\
25 \% \text { Im, 53.6\% S, } \\
21.4 \% \text { W } \\
\text { SEAS: 39.3\% Im, } \\
46.4 \% \text { S, } 14.3 \% \text { W } \\
\text { SpinerCor }{ }^{2}: 28 \% \\
\text { Im, 52\% S and } \\
21 \% \text { W } \\
\text { Sport: } 42 \% \text { Im, } \\
40 \% \text { S, } 18 \% \text { W }\end{array}$ \\
\hline
\end{tabular}

Note: ${ }^{\text {a: }}$ Age presented in mean \pm standard deviation or in range. F: female; M: male; TLSO: thoracolumbosacral orthosis; SEAS: active self-corrective exercises. Im, S, W: \% of subjects who improved $(\mathrm{Im})$, remained stable $(\mathrm{S})$ or worsened $(\mathrm{W})$ the Cobb angle, considering a change $>5^{\circ}$.

Of the 07 studies included, $06(85.7 \%)$ have adopted some kind of kinesiotherapeutic technique in its methodology, while $03(42.9 \%)$ evaluated the results of an intervention with the use of some type of corrective brace. All studies had female sample, and $05(71.4 \%)$ also included male sample. The age group remained between 11.4 and 25 years, of the total of 388 subjects investigated in the studies.

The studies with some kinesiotherapeutic technique had a minimum intervention time of 04 weeks and maximum of two years (mean 37.6 weeks), while studies with corrective brace had a minimum intervention of 08 months reaching up to 02 years (mean 91.6 weeks). Among the 16 different types of interventions, 13 used some kinesiotherapeutic technique and in 08 some corrective brace was used.

Regarding the outcomes in the studies with kinesiotherapeutic technique, 83.3\% (05 of 06) of the studies showed a reduction in spine lateral inclination. With the use of Pilates, Araujo et al. (40) found a 38\% reduction ( $p=0.0001$ ) in Cobb angle. Diab et al. (41) found a reduction of $2.5^{\circ}$ on average, with the physical therapy treatment associated with a forward head correction program. With active self-corrective exercises intervention (SEAS), a clinically significant reduction $\left(>5^{\circ}\right.$ ) of the Cobb angle was observed in $23.5 \%$ and $39.3 \%$ of the patients by Negrini et al. (36) and Zaina et al. (39), respectively; While Negrini et al. (37) found no statistically significant changes $(p>0.05)$ of the Cobb angle. Weiss and Klein (42) demonstrated a statistically significant reduction $(p=0.02)$ of spine lateral inclination in patients undergoing the Schroth method associated with an active exercises physiologic program. Negrini et al. (36) found a worsening $(\mathrm{p}<0.05)$ of spine lateral inclination in subjects treated by conventional physical therapy.

In studies that used some type of corrective brace for treatment of IS, $66.6 \%$ (two of three) reported improvement in progression of spine lateral inclination. Gammon et al. (35) found a little increase in Cobb angle of $6.7^{\circ}$ in patients with SpineCor brace and an increase of $4.8^{\circ}$ in subjects with thoracolumbosacral orthoses. Negrini et al (37) found a statistically significant reduction $(p<0.05)$ of Cobb angle only in the groups wich associated the use of corrective braces $(18,21$ or 23 hours per day) to kinesiotherapy - except the group that used the Risser brace. Zaina et al. (39) showed an improvement $\left(>5^{\circ}\right)$ or stabilization of spine lateral inclination from $78.6 \%$ and $80 \%$ of patients treated with SpineCor brace for 20 hours/day in distint samples, and $82 \%$ of the subjects using SPoRT brace for $18-23 \mathrm{~h} /$ day. The analysis of the results from this last study can not be fully performed, since the authors 
did not provide the absolute values of spine lateral inclination in pre and post intervention moments.

Regarding the methodological quality of the studies (Table 3), evaluated by the PEDro scale, the highest score obtained was of seven points by the study of de Araújo et al. (40). The study of Diab (41) obtained six points. Those of Gammonet al. (35), Negrini et al. (36) and Negrini et al. (37) completed four points. While the studies by Weiss and Klein (42) and Zaina et al. (39) scored three points.

Table 3 - Methodological quality of included studies

\begin{tabular}{lc}
\hline Study & PEDro Scale \\
\hline de Araujo et al. (40) & $7 / 10$ \\
Diab (41) & $6 / 10$ \\
Gammon et al. (35) & $4 / 10$ \\
Negrini et al. (36) & $4 / 10$ \\
Negrini et al. (37) & $4 / 10$ \\
Weiss \& Klein (42) & $3 / 10$ \\
Zaina et al. (39) & $3 / 10$ \\
\hline
\end{tabular}

\section{Discussion}

The studies which presented a statistically significant reduction of the spine lateral inclination on the IS were those with exclusively composed of kinesiotherapeutic techniques treatments $(40,41$, 36,42 ) or associating kinesiotherapy with the use of corrective orthosis (37). Comparisons between absolute values or percentage of the reduction of the spine lateral inclination and the studies are difficult, due to the heterogeneity of spine lateral inclination initial values in the study samples, ranging from $7.1 \pm 2.8^{\circ}(40)$ to $34,5 \pm 3.9^{\circ}$ (37).

However, the group that achieved a greater reduction in absolute value of the curvature was the corrective brace $21 \mathrm{~h} /$ day associated with exercise from the Negrini et al. study (37), reaching a reduction of $7.5 \pm 6.4^{\circ}(p<0,05)$ of Cobb angle. This fact may have occurred due to the long treatment period ( $4.2 \pm 1.4$ years), the largest of all the studies included in this review. It can still be explained by the association of different therapeutic techniques: combining the postural corrective forces of brace used for an extended period daily, with the effects of strengthening exercises, mobilization and increased range of motion.
From the studies that evaluated the effects of a kinesiotherapeutic technique on IS, $83.3 \%$ found a decrease in the curve; while only the conventional phyisical therapy group of Negrini et al. (36) obtained an increase of the Cobb angle of $1.38^{\circ}(\mathrm{p}<0.05)$. Among the studies with corrective brace, $66.7 \%$ showed or a reduction of the curve magnitude or a higher rate of subjects with improvement or stabilization of the curve; meanwhile only Gammon et et al. (35) detected an increase in the Cobb angle after intervention. It is noteworthy that the study of Gammon et al. (35) was the only one that did not use any kinesiotherapeutic technique in any of its treatment groups.

Concerning the duration time of interventions, it is clear that, in general, studies with treatments based on kinesiotherapeutic techniques (37.6 weeks) had shorter duration of intervention than studies with corrective braces ( 91.6 weeks). This temporal discrepancy of follow-up from the subjects being treated may influence the analyzed outcomes, mainly due to the progressive characteristics of the scoliotic curvatures (43).

Despite the use of kinesiotherapy, the movement practices were diverse among the studies, being: Pilates method (40), muscle stretching and strengthening (41), postural correction (41), self corrective exercises $(36,39,37)$, conventional physical therapy (36) and active exercises (37, 42). Such technique diversity makes it difficult to summarize the results together.

The studies performed 16 different types of intervention, demonstrating a heterogeneity in the therapeutic conduct adopted in the treatment of IS. Considering that only one study did not include any type of kinesiotherapeutic intervention, one can perceive a considerable interest in the outcomes resulting from this practice on IS.

As to the methodological quality of the included studies, 07 articles have obtained an average of 4.42 on the PEDro scale. A lack of protocols standardization and techniques in studies with kinesiotherapy is percieved. Even when referring to the use of physical therapy, the studies in general present precarious details of the exercises and periodization strategies.

These methodological characteristics and design diversity among the studies should be considered during the interpretation and summarization of the results. Therefore, it is suggested the future realization of clinical trials with greater internal 
validity (randomized and secret allocation, initially homogeneous groups, blinding, evaluation of all subjects) and greater statistical robustness (intergroup comparisons, and presentation of precision and variability data).

This systematic review has some methodological characteristics that enhace its evidence level, among them: formulation of a delimited research problem, a broad and reproducible search in different databases, clearly defined eligibility criteria, and independent studies evaluated by two reviewers. The studies results analysis should be done with some caution, considering the wide variety of protocols presented with 16 different types of interventions performed.

Therefore the most effective noninvasive interventions to improve the spine lateral inclination in IS were those that associated daily use of a corrective brace with physical exercises to strengthen, mobilize and improve the range of motion, or that which used only kinesiotherapeutic techniques. In this way, it is assumed that the corrective forces of the continuous use of the braces are optimized by the postural musculature training, muscle flexibility improvement and voluntary correction of the posture.

\section{Conclusion}

This systematic review demonstrates a general improvement in the progression of spine lateral inclination on IS of female and male subjects from 11 to 25 years of age submitted to interventions with kinesiotherapeutic techniques and/or corrective braces. The treatment associating kinesiotherapeutic techniques with corrective brace had the highest absolute reduction of spine lateral inclination.

These results however should be interpreted with caution, considering the methodological quality and differences in the studies intervention protocols. We suggest therefore the realization of more clinical trials with similar protocols of intervention and better methodological robustness.

\section{Acknowledgments}

The authors would like to thank FAPERGS and CAPES for their financial support during this study.

\section{References}

1. Bassani E, Candotti CT, Passini M, Melo M, La Torre M. Assessment of neuromuscular activation in individuals with scoliosis using surface electromyography. Rev Bras Fisioter. 2008;12(1):13-9.

2. Lonstein JE. Scoliosis: surgical versus nonsurgical treatment. Clin Orthop Relat Res. 2006;443:248-59.

3. Weinstein SL, Dolan LA, Cheng JC, Danielsson A, Morcuende JA. Adolescent idiopathic scoliosis. Lancet. 2008;371(9623):1527-37.

4. Bunnel WP. The natural history of idiopathic scoliosis before skeletal maturity. Spine (Phila Pa 1976). 1986;11(8):773-6.

5. Lenssinck M-LB, Frijlink AC, Berger MY, BiermanZeinstra SMA, Verkerk K, Verhagen AP. Effect of bracing and other conservative interventions in the treatment of idiopathic scoliosis in adolescents: a systematic review of clinical trials. Phys Ther. 2005;85(12):1329-39.

6. Herring JA. Scoliosis. Tachdjian's Pediatric Orthopedics. Philadelphia: Saunders, WB; 2002. p. 213.

7. Reamy BV, Slakey JB. Adolescent idiopathic scoliosis: review and current concepts. Am Fam Physician. 2001;64(1):111-6.

8. Carrasco MIB, Ruiz MCS. Imagen percibida en la escoliosis idopática adolescente: revisión integrativa de la literatura. Rev da Esc Enferm da USP. 2014;48(4):748-58.

9. Matamalas A, Bagó J, D'Agata E, Pellisé F. Body image in idiopathic scoliosis: a comparison study of psychometric properties between four patientreported outcome instruments. Health Qual Life Outcomes. 2014;12:81.

10. Leszczewska J, Czaprowski D, Pawlowska P, Kolwicz A, Kotwicki T. Evaluation of the stress level of children with idiopathic scoliosis in relation to the method of treatment and parameters of the deformity. Sci World J. 2012;2012:538409.

11. Sevastikoglou JA, Linderholm H, Lindgren U. Effect of the Milwaukee brace on vital and ventilatory capacity of scoliotic patients. Acta Orthop Scand. 1976;47(5):540-5. 
12. Nault ML, Allard P, Hinse S, Le Blanc R, Caron $\mathrm{O}$, Labelle $\mathrm{H}$, et al. Relations between stand-up stability and body posture parameters in adolescent idiopathic scoliosis. Spine (Phila Pa 1976). 2002;27(17):1911-7.

13. Chen PQ, Wang JL, Tsuang YH, Liao TL, Huang PI, Hang YS. The postural stability control and gait pattern of idiopathic scoliosis adolescents. Clin Biomech. 1998;13 (1 Suppl 1):S52-8.

14. Pialasse J, Descarreaux M, Mercier P, Blouin J. The vestibular-evoked postural response of adolescents with idiopathic scoliosis is altered. PLoS One. 2015;10(11):e0143124.

15. Bonorino KC, Borin G da S, da Silva AH. Tratamento para escoliose atráves do método iso-stretching e uso da bola suíça. Cinergis. 2007;8(2):1-5.

16. Dudin MG, Pinchuk DY. Idiopathic scoliosis: diagnostic and pathogenisis. The Man. St. Petersburg; 2009. p. 335.

17. Kwok G, Yip J, Cheung M, Yick K. Evaluation of myoelectric activity of paraspinal muscles in adolescents with idiopathic scoliosis during usual standing and sitting. Biomed Res Int. 2015;2015:958450.

18. Danielsson AJ, Hasserius R, Ohlin A, Nachemson AL. A prospective study of brace versus observation alone in adolescent idiopathic scoliosis: the follow-up mean of 16 years after maturity. Spine (Phila Pa 1976). 2007;32(20):2198-207.

19. Weinstein SL, Dolan LA, Spratt KF, Peterson KK, Spoonamore MJ, Ponstei IV. Health and function of patients with untreated idiopathic scoliosis: a 50-year natural history study. JAMA. 2003;289(5):559-67.

20. Newton PO, Wenger DR. Idiopathic and congenital scoliosis. In: Morrisey RT, Weinstein SL, editors. Lowell and Winter's Pediatric Orthopedics. Philadelphia: Lippincott Williams and Wilkins; 2001. p. 677-740.

21. Dickson RA, Weinstein SL. Bracing (and screening) yes or no? J Bone Joint Surg Br. 1999;81(2):193-8.

22. Chan A, Lou E, Hill D. Review of current technologies and methods supplementing brace treatment in adolescent idiopathic scoliosis. J Child Orthop. 2013;7(4):309-16.
23. Kim HS. Evidence-based nonoperative treatment in adolescent idiopathic scoliosis. Asian Spine J. 2014;8(5):695-702.

24. Kotwicki T, Jozwiak M. Conservative management of neuromuscular scoliosis: personal experience and review of literature. Disabil Rehabil. 2008;30(10):792-8.

25. Mordecai SC, Dabke H V. Efficay of exercise therapy for the treatment of adolescent idiopathic scoliosis: a review of the literature. Eur Spine J. 2012;21:382-9.

26. Negrini S, Atanasio S, Zaina F, Romano M. Rehabilitation of adolescent idiopathic scoliosis: results of exercises and bracing from a series of clinical studies. Europa Medicophysica-SIMFER 2007 Award Winner. Eur J Phys Rehabil Med. 2008;44(2):169-76.

27. Stehbens WE, Cooper RL. Regression of juvenile idiopathic scoliosis. Exp Mol Pathol. 2003;74(3):326-35.

28. Shin JH, Jun SL, Lee YJ, Kim JH, Hwang SY, Ahn $\mathrm{SH}$. Effects of intermittent traction therapy in an experimental spinal column model. J Acupunt Meridian Stud. 2014;7(2):83-91.

29. Anwer S, Alghadir A, Shaphe A, Anwar D. Effects of exercise on spinal deformities and quality of life in patients with adolescent idiopathic scoliosis. Biomed Res Int. 2015;2015:123848.

30. Yang JM, Lee JH, Lee DH. Effects of consecutive application of stretching, Schroth, and strengthening exercises on Cobb's angle and the rib hump in an adult with idiopathic scoliosis. J Phys Ther Sci. 2015;27(8):2667-9.

31. Schlenzka D, Yrjönen T. Bracing in adolescent idiopathic scoliosis. J Child Orthop. 2013;7(1):51-5.

32. Weiss HR, Goodall D. The treatment of adolescent idiopathic scoliosis (AIS) according to present evidence: a systematic review. Eur J Phys Rehabil Med. 2008;44(2):177-93.

33. Araújo MEA, Silva EB, Mello DB, Cader SA, Salgado ASI, Dantas EHM. The effectiveness of the Pilates method: reducing the degree of non-structural scoliosis, and improving flexibility and pain in female college students. J Bodyw Mov Ther. 2012;16(2):191-8. 
34. Diab AA. The role of forward head correction in management of adolescent idiopathic scoliotic patients: a randomized controlled trial. Clin Rehabil. 2012;26(12):1123-32.

35. Gammon SR, Mehlman CT, Chan W, Heifetz J, Durrett G, Wall EJ. A comparison of thoracolumbosacral ortheses and SpineCor treatment of adolescent idiopathic scoliosis patients using the scoliosis research society standardized criteria. J Pediatr Orthop. 2010;30(6):531-8.

36. Negrini S, Zaina F, Romano M, Negrini A, Parzini $S$. Specific exercises reduce brace prescription in adolescent idiopathic scoliosis: a prospective controlled cohort study with worst-case analysis. J Rehabil Med. 2008;40(6):451-5.

37. Negrini S, Atanasio S, Fusco C, Zaina F. Effectiveness of complete conservative treatment for adolescent idiopathic scoliosis (bracing and exercises) based on SOSORT management criteria: results according to the SRS criteria for bracing studies. Scoliosis. 2009;4:19.

38. Weiss HR, Klein R. Improving excellence in scoliosis rehabilitation: a controlled study of matched pairs. Pediatr Rehabil. 2006;9(3):190-200.

39. Zaina F, Donzelli S, Negrini A, Romano M, Negrini S. SpineCor, exercise and SPoRT rigid brace: what is the best for Adolescent Idiopathic Scoliosis? Short term results from 2 retrospective studies. Stud Health Technol Inform. 2012;176:361-4.
40. Araujo MEA, Silva EB, Mello DB, Cader SA, Salgado ASI, Dantas EHM. The effectiveness of the Pilates method: reducing the degree of non-structural scoliosis, and improving flexibility and pain in female college students. J Bodyw Mov Ther. 2012;16(2):191-8.

41. Diab AA. The role of forward head correction in management of adolescent idiopathic scoliotic patients: a randomized controlled trial. Clin Rehabil. 2012;26(12):1123-32.

42. Weiss HR, Klein R. Improving excellence in scoliosis rehabilitation: A controlled study of matched pairs. Pediatr Rehabil. 2006;9(3):190-200.

43. Coillard C, Circo AB, Rivard $\mathrm{CH}$. A prospective randomized controlled trial of the natural history of idiopathic scoliosis versus treatment with the SpineCor brace. Eur J Phys Rehabil Med 2014;50(5):479-87.

Received in 11/27/2015

Recebido em 27/11/2015

Approved in 10/25/2016

Aprovado em 25/10/2016 